Anales de Geografía de la Universidad Complutense ISSN: 0211-9803

http://dx.doi.org/10.5209/AGUC.55959

\title{
Contrastes e inequidades en los territorios intermedios de la Región Metropolitana de Rosario, Argentina
}

\author{
Cecilia Inés Galimberti ${ }^{1}$ \\ Recibido: 26 de enero del 2016 / Enviado a evaluar: 10 de julio del 2016 / Aceptado: 16 de diciembre del 2016
}

Resumen. Los territorios intermedios de las regiones metropolitanas atraviesan, especialmente desde las últimas décadas del siglo XX, una acelerada transformación caracterizada por una mayor ocupación del suelo. Si bien estas dinámicas se registran a nivel mundial, en los ámbitos metropolitanos de América Latina se identifica una profundización de las desigualdades y contrastes socio-espaciales. Por lo cual, tomando como caso de estudio la Región Metropolitana de Rosario -Argentina-, el presente artículo analiza críticamente las nuevas urbanizaciones que se desarrollan en estos territorios y su relación con las poblaciones marginales pre-existentes. A través de una metodología cualitativa, de tipo argumentativainterpretativa, buscamos la comprensión de estos procesos dinámicos de transformación. Los resultados verifican la profundización y complejización de los procesos de segregación urbana e impactos ambientales que requieren el desarrollo de nuevos instrumentos y estrategias de planeamiento que den lugar a las crecientes demandas, pero construyendo mayores niveles de integración socio-espacial.

Palabras clave: Territorios intermedios; desigualdad; urbanizaciones cerradas; asentamientos irregulares; Región Metropolitana de Rosario; suburbanización.

\section{[en] Contrasts and inequities in the in-between territories of the Metropolitan Region of Rosario, Argentina}

\begin{abstract}
The in-between territories of metropolitan regions cross, especially from the last decades of the 20th century, an intensive transformation characterized by a greater land occupation. While these dynamics register worldwide, in the metropolitan areas of Latin America a deepening of inequalities and socio-spatial contrast is identified. Therefore, taking as a case study the Metropolitan Region of Rosario Argentina-, this article discusses critically the new developments taking place in these territories and their relationship with the pre-existing marginal populations. Through a qualitative methodology, argumentative - interpretive type, we look for the comprehension of these dynamic processes of

1 Consejo Nacional de Investigaciones Cinéticas y Técnicas (CONICET). Centro Universitario de Investigaciones Urbajas y Regionales (CURDIUR). Facultad de Arquitectura, Planeamiento y Diseño. Universidad Nacional de Rosario (Argentina).

E-mail: celia.galimberti@conicet.gov.ar
\end{abstract}


transformation. The results verify the deepening and complexity of the processes of urban segregation and environmental impacts that require the development of new instruments and planning strategies that give rise to growing demands, but building higher levels of socio-spatial integration.

Key words: In between; inequality; gated communities; informal settlements; Metropolitan Region of Rosario; urban sprawl.

\section{[fr] Contrastes et inègalitès dans les territoires intermédiaires de la Region Metropolitaine de Rosario, Argentina}

Résumé. Les territoires intermédiaires des régions métropolitaines connaissent, en particulier depuis les dernières décennies du XXe siècle, une accélération de la transformation caractérisée par une plus grande de l'occupation du sol. Si ces dynamiques sont enregistrés au niveau mondial dans les domaines métropolitains d'Amérique latine s'identifie un approfondissement des inégalités et de contrastes sociospatiales. Par conséquent, en prenant comme cas d'étude de la région métropolitaine de Rosario Argentine -, le présent article analyse critique des nouvelles villages qui se développent dans ces territoires et leur relation avec les populations marginales pré-existants. Par le biais d'une méthode qualitative, de type argumentativa-interprétative, nous recherchons la compréhension de ces processus dynamiques de transformation. Les résultats vérifier l'approfondissement et la complexité des processus de ségrégation urbaine et des impacts environnementaux qui nécessitent le développement de nouveaux instruments et stratégies de planification qui donnent lieu à une demande croissante, mais de construire des niveaux plus élevés d'intégration socio-spatiale.

Mots clés: Territoires intermédiaires; l'inégalité; les établissements informels; quartiers fermés; Région Métropolitaine de Rosario; l'étalement urbain.

Cómo citar. Galimberti, C.I. (2017): Contrastes e inequidades en los territorios intermedios de la Región Metropolitana de Rosario, Argentina. Anales de Geografía de la Universidad Complutense, 37(1), 135159.

Sumario. 1. Introducción. 2. Territorios intermedios: espacio de contrastes. 3. Área de estudio: Región Metropolitana de Rosario. 4. Contrastes en los territorios intermedios de la Región Metropolitana de Rosario. 4.1. Corredor sur: Nuevas demandas sobre el paisaje fluvial metropolitano. 4.2. Corredor oeste: El acelerado incremento de nuevas urbanizaciones en el territorio de la RMR. 5. Conclusiones. 6. Bibliografía.

\section{Introducción}

La expansión de la ciudad y la dispersión urbana son fenómenos que se registran a escala global desde la segunda mitad del siglo XX y, en la actualidad, presentan características y dinámicas de complejidad creciente. Los procesos de suburbanización y difusión territorial transforman las regiones metropolitanas en todo el mundo, a través del cambio de usos del suelo que responden mayormente a las demandas del mercado. 
El presente artículo se propone analizar críticamente las transformaciones residenciales que se identifican en los territorios intermedios ${ }^{2}$ de las regiones metropolitanas de América Latina. Estos espacios "entre-ciudades", si bien presentan características análogas a nivel mundial, poseen diferencias y particularidades a cada contexto específico. A diferencia de Europa o Norteamérica, los paisajes intermedios de Latinoamérica registran altos niveles de desigualdad, segregación social y fragmentación territorial. Se identifican así, dinámicas de urbanización contrastantes. Por ejemplo, existen diversos procesos migratorios hacia las grandes ciudades, que al no poder acceder al mercado formal de tierras urbanas, o por motivos laborales ${ }^{3}$, ocupan ilegalmente suelo periurbano -mayormente sin infraestructuras ni servicios-, conformando asentamientos irregulares ${ }^{4}$. Pero, por otro lado, también numerosas familias -generalmente de clase alta y media-alta ${ }^{5}$ - eligen vivir en urbanizaciones cerradas localizadas en estos paisajes intermedios. Se registran, en un mismo ámbito territorial, viviendas que no acceden a necesidades básicas en yuxtaposición a residencias de categoría que se muestran como símbolo de una mejor calidad de vida.

El incremento de nuevas urbanizaciones, alejadas de los centros históricos tradicionales, en las áreas suburbanas de las ciudades latinoamericanas, es un fenómeno creciente y acelerado especialmente desde las décadas de 1980 y 1990. Principalmente, estas transformaciones se deben a profundos cambios políticos, económicos y sociales que se reflejan en nuevos desarrollos territoriales, fuertemente asociados a promotores privados (Torres, 2001; Janoschka, 2002; Hidalgo, 2004). Simultáneamente, estos nuevos procesos han ocasionado un mayor desplazamiento de los grupos más pobres hacia las periferias urbanas, denotando nuevos frentes de segregación residencial (Clichevsky, 2000; Kaztman, 2008; Sabatini y Brain, 2008). De este modo, la periferia metropolitana, en numerosas ciudades latinoamericanas, refleja espacios disparejos entre la oposición de barrios cerrados de lujo y villas miseria, sin poder encontrar mayormente una adecuada forma de integración socioespacial (Vidal-Koppmann, 2007).

2 Zwischenstadt, según Thomas Sieverts (2004); término alemán utilizado para referirse a las transformaciones territoriales en los espacios periurbanos o entre-ciudades. El mismo ha sido traducido al inglés como cities without cities o in between y al español como "entre ciudad" o "paisajes intermedios". En el presente artículo, nos vamos a referir a estos espacios como "territorios intermedios".

3 Generalmente oficios hortícolas, agrícolas, pesca, entre otros, que suelen estar relacionados a condiciones inestables de empleo.

4 Se define "asentamiento irregular a todo conjunto de viviendas afincadas sobre terrenos públicos y/o privados, siendo sus habitantes ocupantes ilegales de los mismos" (Piccolo et. al., 1992). En América Latina, se utilizan diversas denominaciones para referirse a éstos, por ejemplo: callampas, en Chile; favelas, en Brasil; barriadas, en Perú; entre otros.

5 Es importante remarcar que también existen familias de clase media que se encuentran entre estos dos extremos. Por ejemplo, es el caso de habitantes que, al no poder acceder a una vivienda propia en las ciudades -por su alto valor económico-, compran parcelas en sectores periurbanos a un costo bajo -dado que mayormente carecen de infraestructuras y servicios- y construyen su vivienda, generando así nuevas urbanizaciones alejadas de los poblados existentes. 
En este contexto, la presente investigación toma como caso de estudio al territorio intermedio de la Región Metropolitana de Rosario (RMR), Argentina. Para lo cual, se abordan dos sectores específicos representativos de la transformación acelerada de sus espacios "entre-ciudades" que se registran en los últimos años y que exhiben fragmentaciones y segregaciones socio-espaciales: corredor sur y corredor oeste. Se propone así reflexionar sobre las relaciones -o falta de ellas- de estos modos de habitar contrastantes -urbanizaciones cerradas y asentamientos irregulares- y contribuir al debate contemporáneo de los procesos acelerados de metropolización en contextos latinoamericanos y sus efectos resultantes -morfológicos, sociales y ambientales-.

Este estudio se realiza principalmente desde una metodología cualitativa, ya que se trata de captar los elementos claves de la realidad estudiada, sus lógicas y reglas implícitas y explícitas. Las principales fuentes utilizadas son: bases georreferenciadas del Servicio de Catastro e Información Territorial de la provincia de Santa Fe; cartografías del período 1980-2010 de las distintas municipales analizadas; imágenes satelitales históricas y actuales de dichas municipalidades disponibles en Google Earth; imágenes de Google Street View; ordenanzas de usos del suelo y planes urbanos de los municipios estudiados; archivo diario La Capital. La información fue confirmada por trabajo de campo llevado a cabo con la asistencia cualificada de actores locales, a través del cual se tomaron registros fotográficos y cartográficos de los cambios de usos del suelo, el desarrollo de nuevas urbanizaciones y su relación con las preexistentes. Asimismo, se realizaron entrevistas semi-estructuradas a distintos referentes de la región -actores institucionales y ciudadanos-.

Se articula así, el análisis morfológico de las transformaciones territoriales realizadas en las últimas tres décadas, en relación a las políticas de planificación urbana que intervienen en la producción de ciudades -abiertas o cerradas-, el rol del gobierno y los distintos niveles estatales; los impactos y efectos socio-ambientales resultantes de dichas transformaciones y las percepciones sociales sobre los mismos.

\section{Territorios intermedios: espacio de contrastes}

Los acelerados procesos de urbanización que suceden en los territorios intermedios, tienden a presentar una utilización extensiva y expansiva del espacio, incrementando la movilidad -tanto de personas como de mercancías-, producto de la dispersión de las actividades y la población (Font, 2011). Se registra un cambio en las dinámicas tradicionales del crecimiento urbano, dado que existe una tendencia al incremento de habitantes en el ámbito periurbano o en la periferia de los núcleos centrales metropolitanos.

Numerosos estudios, desde mediados del siglo XX, analizan las transformaciones del espacio metropolitano y de sus territorios situados entre núcleos urbanos. Pierre George, en 1950, realiza un valioso aporte sobre la banlieue de París -las afueras-; como también George Wehrwein, en 1942, al estudiar los suburbios anglosajones acuña el término rural-urban fringe -franja urbano-rural-. Asimismo, Raymond Pahl, 
en 1965, introduce la noción de rural-urban continuum -continuo urbano-rural-. Es en 1967, para designar las inconexas periferias norteamericanas, que Jean Racine introduce el término periurbano y al proceso de formación de las mismas lo llama metamorfismo periurbano, caracterizado por la desnaturalización de las estructuras urbanas y rurales (Valenzuela Rubio, 1985). El concepto de periurbano es ampliamente utilizado en las décadas posteriores para comprender los procesos de transformación que atraviesa la interfase urbano-rural.

A fines de la década de 1990, Thomas Sieverts incorpora el concepto de Zwischenstadt ${ }^{6}$, en pos de focalizar las transformaciones recientes que se desarrollan en los espacios intermedios o entre-ciudades de las urbanizaciones metropolitanas. Este término, en relación a la noción tradicional de periurbano, hace foco especialmente en la características de estos ámbitos de estar "entre"; ya sea, entre los centros históricos urbanos y el campo, entre el lugar como espacio de vida y los nolugares del movimiento, entre los pequeños ciclos de las economías locales y la dependencia del mercado global: "El término Zwischenstadt, significa que la ciudad de hoy está en un estado "intermedio", un estado entre el lugar y el mundo, espacio y tiempo, ciudad y campo"7 (Sieverts, 2004).

Los territorios intermedios dan la impresión de carecer de planificación previa y de conformarse a través de un gran número de decisiones individuales; las cuales, a su vez, presentan una gran influencia de las demandas del capitalismo y las economías neoliberales. Se denotan así como territorios híbridos, dado que, en estos espacios, siguiendo a Douglas Young et. al. (2011), se despliega una gran cantidad de usos y actividades inconexas -generalmente atípicas a los centros urbanos y a los clásicos suburbios- que presentan una gran segregación. Si bien se identifican rupturas y fragmentaciones en los paisajes entre-ciudades europeos y norteamericanos, las mismas poseen mayor profundidad en los contextos latinoamericanos.

La reestructuración causada por el capitalismo a escala mundial e incrementada por las reformas institucionales y macroeconómicas, en América Latina ha ocasionado cambios notables en la configuración territorial, en las políticas públicas, en la planificación urbana y en las concepciones sobre la ciudad. Si bien se han creado nuevas oportunidades también se han agudizado las desigualdades inter e intra urbanas, provocando una radical transformación y una intensa fragmentación espacial y sociocultural (Cuenya, 2000). Ahora bien... ¿de qué hablamos cuando hablamos de fragmentación? Como explica Prévôt-Schapira (2001), este término supone que lo que debería tener un funcionamiento global, ha estallado en múltiples unidades y se ha perdido la unidad del conjunto urbano. Engloba así una multiplicidad de manifestaciones metafóricas y geográficas que inciden en diversos aspectos de la vida cotidiana:

6 En el libro denominado: "Zwischenstadt: Zwischen Ort und Welt, Raum und Zeit, Stadt und Land", que podemos traducir como: Paisajes intermedios: entre el lugar y el mundo, espacio y tiempo, ciudad y campo.

7 Traducido por la autora. Texto original: "The term Zwischenstadt signifies that today's city is in an 'in between' state, a state between place and world, space and time, city and country". 
El término se emplea para analizar un fenómeno cada vez más frecuente en la gran metrópolis latinoamericana, la proximidad de ricos y pobres, pero en espacios herméticamente cerrados, lo que establece relaciones asimétricas entre las dos partes de la ciudad. (...) La materialización cada día más visible de los procesos de separación, de aislamiento -exclusión y archipielización-, mediante muros, rejas, barreras, “aduana privadas”.

(Prévôt-Schapira, 2001:39)

En este sentido, junto al proceso de urbanización se produce una fractura social que se traduce en formas específicas de segregación ${ }^{8}$ a través de verdaderos guetos de pobreza (Svampa, 2001), que tienen su contraparte en el desarrollo de urbanizaciones privadas de categoría, elegidas por las clases altas y medias-altas. La segregación urbana, en términos generales, como explica Duhau (2013), se entiende como la desigual distribución espacial en la ciudad de distintos grupos sociales definidos sobre todo en términos de clase o estratos sociales, pertenencia étnica, características raciales y preferencias religiosas. En el caso de América Latina, el aspecto más relevante es la primera, referida a los estratos socioeconómicos ${ }^{9}$. Pero, debido a su complejidad, la segregación requiere una definición compuesta para dar cuenta de aspectos diferenciables tanto en términos de sus impactos sociales y urbanos como referentes a la política pública. Siguiendo a Sabatini (2003), se diferencian tres dimensiones: 1. El grado de concentración espacial de los grupos sociales; 2. La homogeneidad que presentan las distintas áreas internas urbanas; y, 3. El prestigio social -o falta del mismo- de las distintos sectores o barrios de la ciudad. Se comprenden, entonces, como dimensiones objetivas de la segregación, las dos primeras, y dimensiones subjetivas, vinculada a la percepción social, la tercera.

La ciudad latinoamericana presenta así, diversas formas complejas de segregación residencial y, especialmente desde la década de 1980, se desarrollan nuevos cambios respecto a los patrones tradicionales de segregación ${ }^{10}$. Éstos son resultantes de nuevas dinámicas, como por ejemplo: la apertura de alternativas de desarrollo residencial para las elites o grupos medios altos, fuera de las áreas tradicionales de concentración -muchas veces entre asentamientos de bajos ingresos-; la emergencia de nuevos subcentros -comerciales y de servicios- fuera del centro, generalmente en el cruce de vías radiales y circunvalares -donde se pueden conseguir extensas áreas de mercado-; la generalización de la tendencia del alza del precio del suelo en el conjunto urbano -

8 La segregación se manifiesta no solo desde un aspecto físico-material, sino comprende lo social, ideológico y jurídico. En este sentido, al hablar de marginalidad, nos referimos a una "integración no alcanzada" (De Castro et al., 1996), a un derecho limitado, a la separación entre aquellos que tienen acceso a la ciudad y los que no.

9 Como explica Sabatini (2003) las fuertes desigualdades sociales, de ingreso y de rango o clase social representan tal vez la característica más saliente de la estructura social de en las ciudades latinoamericanas.

10 El patrón tradicional de segregación latinoamericano, presenta los siguientes rasgos: 1. Marcada concentración espacial de los grupos altos y los medios ascendentes ("barrios de alta renta"); 2. La conformación de amplias áreas de alojamiento de los grupos pobres, mayoritariamente en la periferia lejana y mal servida; 3. La diversidad social de los "barrios de alta renta", ya que además de las elites viven grupos medios e incluso bajos (Sabatini, 2003). 
ocasionando la localización de viviendas de sectores de ingresos bajos fuera de la ciudad, hacia la región circundante-; la aparición de nuevas formas de crecimiento residencial discontiguas respecto a la ciudad, agregando así alternativas al crecimiento dominante tipo mancha de aceite; la renovación urbana de áreas centrales deterioradas para usos residenciales o terciaros, como a la edificación residencial en altura para grupos medios o medios-altos (Sabatini, 2003).

Los asentamientos irregulares que se incrementan o emergen en la periferia y los grupos que se auto-segregan dentro de comunidades cerradas no solo transforman el paisaje urbano con sus características particulares, sino que también crean nuevos escenarios donde la proximidad física entre los distintos modos de habitar conduce a una segregación residencial asegurada por los límites materiales que dividen las áreas de los distintos grupos socio-económicos. El rol del mercado y de los promotores inmobiliarios resulta central en las nuevas dinámicas de transformación del paisaje intermedio metropolitano, dado que restringe el acceso al espacio urbano y tiene una fuerte influencia en las distintas prácticas y representaciones de los diferentes grupos sociales, ya que induce directamente sobre donde se asientan las familias, direccionando o reforzando así, los efectos de la segregación (Michelini y Pintos, 2016).

De este modo, siguiendo a Mongin (2006), la ciudad que antes prometía integración, solidaridad y seguridad ha sido reemplazada por una ciudad que separa los grupos y las comunidades manteniéndolos a distancia. Se crean entonces, ciudades dentro de ciudades, enclaves cerrados, ajenos a las dinámicas del poblado o de la jurisdicción donde se insertan; produciendo nuevos conflictos espaciales y sociales a las comunidades preexistentes. Existe, de esta manera, un cambio cultural en las lógicas del habitar donde el espacio público de sociabilización tiende a ser rechazado, cercenando así los principios básicos de la civitas. La ciudad, entonces, se fragmenta y se aísla.

Asimismo, debido a la gran dispersión y expansión en el territorio, estos modelos de urbanización conducen al incremento de movilidad, especialmente al uso del automóvil individual. Se plantea un escenario "automóvil-intensivo" (Blanco y San Cristóbal, 2012) y la subordinación de otras movilidades -como transporte público, bicicleta o pie-, dado éstas quedan relegadas frente a los grandes desplazamientos de nodos dispersos en el territorio. Esta tendencia, además de ser insustentable, también contribuye a profundizar las desigualdades y la fragmentación, ya que, si bien los habitantes de las urbanizaciones cerradas dispersas se movilizan a través de sus vehículos particulares por medio de las vías rápidas -como autopistas-, los sectores de bajos ingresos, a veces situados entre estos grandes enclaves privados-, generalmente sólo acceden a otros modos de movilidad (aunque en muchos casos el transporte público sea ineficiente -o incluso no haya-, o el transporte a pie o en bicicleta no sea adecuado por la falta de caminos en buen estado o por las grandes distancias).

Estos paisajes de la desigualdad son objeto de una construcción social de gran complejidad que denuncia las relaciones de exclusión existentes entre la ciudad formal y la informal, tanto espacial como social, resultado de diversas ambigüedades a lo largo del tiempo. Esta situación conlleva a reflexionar sobre las zonas de tensión 
entre realidades diversas, sobre quiénes son considerados ciudadanos y quiénes no, sobre qué es considerado ciudad y qué no (Tardín Coelho, 2007). Por consiguiente, identificamos una situación territorial y social de difícil lectura y comprensión en su totalidad, que denuncia la complejidad de nuestros territorios urbanos actuales.

\section{3. Área de estudio: Región Metropolitana de Rosario}

La Región Metropolitana de Rosario se encuentra en la pampa ondulada de la República Argentina, a orillas del río Paraná y a $300 \mathrm{Km}$ de la ciudad de Buenos Aires, capital del país. La misma presenta más de $1.400 .000^{11}$ habitantes, siendo la tercera área metropolitana más poblada de Argentina -luego de Buenos Aires y Córdoba-. (Figura 1)

La conformación de Rosario y su región se produce a partir de la segunda mitad del siglo XIX, debido a su privilegiada posición geográfica y estratégica a inmediaciones del río y por diversos sucesos políticos clave de la historia nacional. Es a partir de este período, que en este territorio -prácticamente despoblado- surgen numerosas localidades a partir de la instalación de estaciones ferroviarias.

Aproximadamente entre las décadas de 1930 y 1950 comienza a producirse la conurbación de gran parte del sector norte de la región, debido a la inauguración de la ruta nacional $\mathrm{N}^{\circ} 11$ y a la instalación de diversas industrias de gran relevancia que atraen a trabajadores a asentarse en estas localidades. Es importante remarcar, que la construcción de todas las infraestructuras viales del área -rutas nacionales y provinciales- cambia las dinámicas de los poblados que atraviesan -generalmente las mismas se realizan cercanas y paralelas a las existentes vías ferroviarias-.

Posteriormente, entre las décadas de 1960 y 1980, se construyen tres vías rápidas de movilidad -autopistas- que vinculan la ciudad central hacia el norte -autopista a Santa Fe-, hacia el oeste -autopista a Córdoba- y hacia el sur -autopista a Buenos aires-. Asimismo, también en este período se construye la Avenida de Circunvalación, cinturón vial que rodea gran parte de la ciudad de Rosario y conecta las mencionadas autopistas. Estas infraestructuras generan nuevas e importantes transformaciones en el territorio intermedio metropolitano, ya que en proximidad a las mismas se producen numerosos cambios en los usos del suelo. Se convierten así grandes extensiones de suelo rural a urbano -ya sea para usos industriales, residenciales, comerciales, recreativos, entre otros-.

11 La cantidad de población de la Región Metropolitana de Rosario varía en relación a la definición de los límites de la misma y respecto a las localidades que se incluyen. 
Figura 1. Localización de la Región Metropolitana de Rosario.

\section{América del Sur}

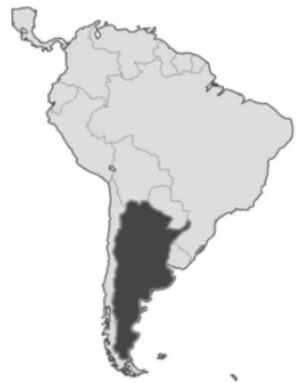

\section{Región Metropolitana de Rosario}

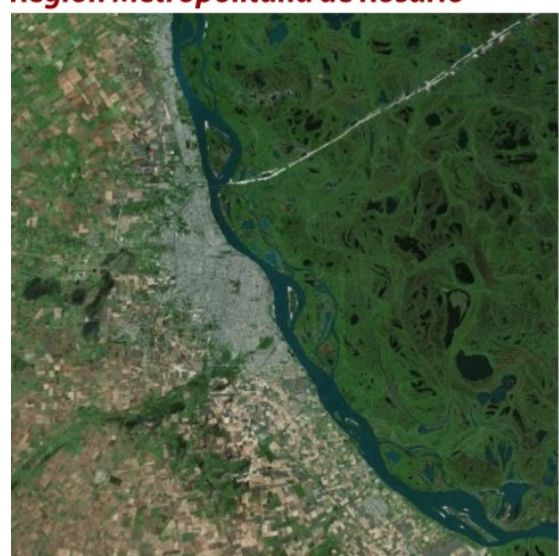

Argentina

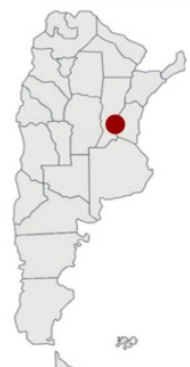

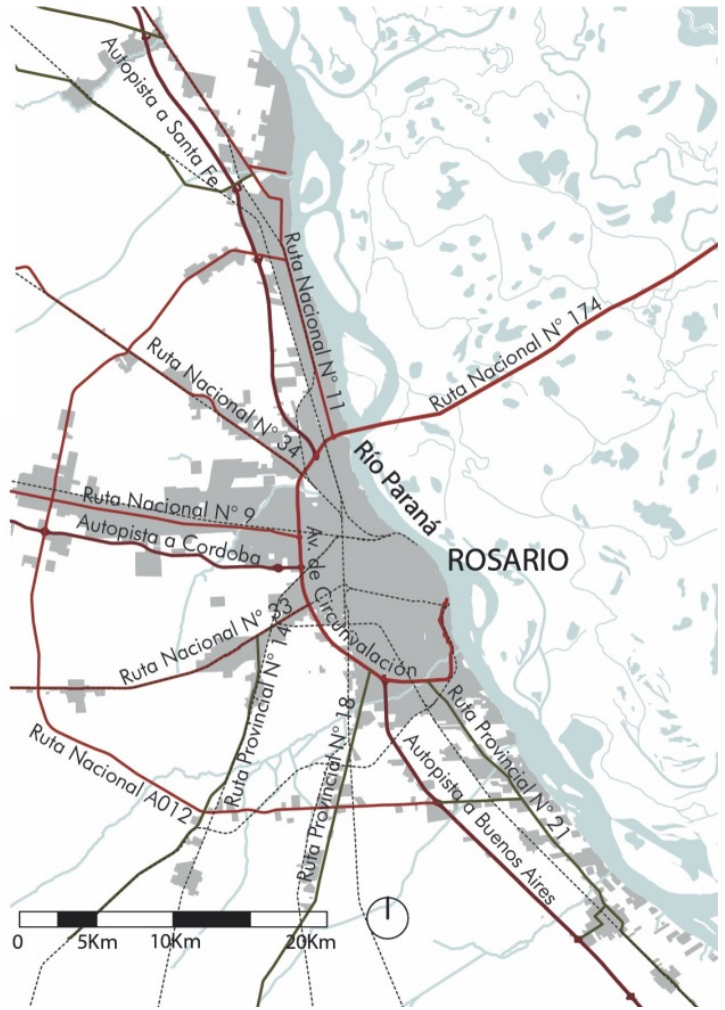

Fuente: Elaboración Propia.

Los avatares socio-políticos-económicos ${ }^{12}$ que suceden -tanto a nivel internacional como nacional- a partir de la década de 1980, ocasionan numerosas transformaciones para la región. La misma se posiciona como polo de exportación de gran relevancia internacional, resultando un nodo estratégico comunicacional y enclave logístico de gran importancia para Sudamérica. Los cambios que ocurren en las últimas décadas en el Gran Rosario son diversos y abarcan distintos frentes temáticos: producción, sociedad, territorio, economía, entre otros; sin embargo, en este artículo nos focalizamos a analizar los contrastes existentes en los paisajes intermedios de esta región, vinculados a los componentes residenciales. Por lo cual, a continuación, nos detendremos en el estudio particularizado de este tema.

12 Gran parte de América Latina padece numerosos procesos dictatoriales durante el siglo XX. Entre las décadas de 1970 y 1980 se recuperan los gobiernos democráticos en la mayoría de los países latinoamericanos. En Argentina se recupera definitivamente la democracia en 1983. A su vez, el contexto internacional marcado por la globalización, el postfordismo, las políticas neoliberales, los cambios del capital y los mercados, afectan directamente a estos países, atravesando diversas transformaciones económicas, sociales y políticas. 


\section{Contrastes en los territorios intermedios de la Región Metropolitana de Rosario}

El territorio intermedio de la región del Gran Rosario se transforma vertiginosamente en las últimas décadas, aumentando en gran medida la ocupación del suelo cambiando de territorio rústico o rural a urbano-. Se registra un notable incremento de población en estos espacios, a través de diversas tipologías de urbanización. En la presente investigación nos enfocamos a analizar aquellas que muestran un complejo proceso de desigualdad que, a pesar de muchas veces encontrarse cercanos espacialmente, están notablemente distantes socialmente y presentan diversas barreras, tanto físicas como inmateriales.

Figura 2. Asentamientos irregulares en la Región Metropolitana de Rosario.

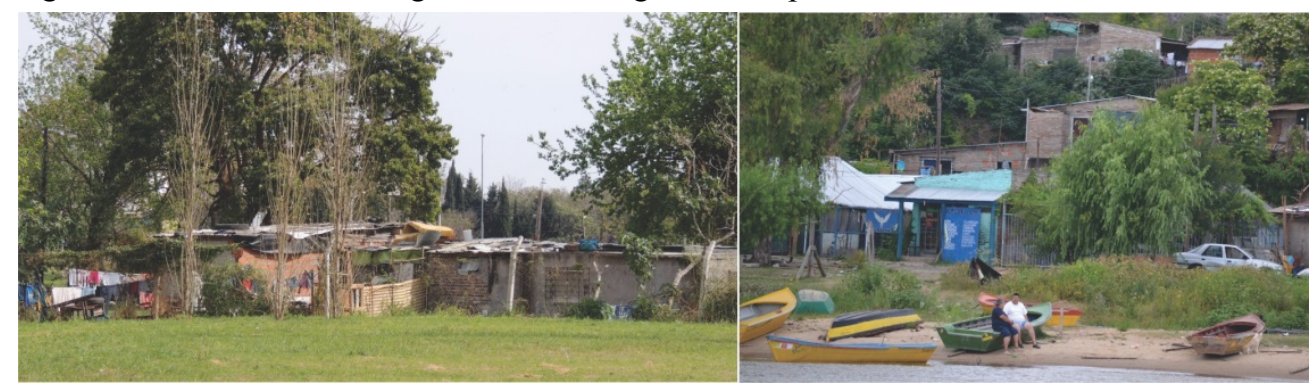

Fuente: Elaboración propia.

Por un lado, se identifican los llamados asentamientos irregulares, que se caracterizan por tener altas condiciones de vulnerabilidad y grandes carencias de infraestructuras y servicios. Sus pobladores mayormente no poseen un trabajo estable y tienen ingresos económicos insuficientes. A su vez, muchos de ellos presentan Necesidades Básicas Insatisfechas ${ }^{13}$. Gran parte de los asentamientos irregulares en el sector de estudio datan de mediados del siglo XX, surgiendo a partir de procesos migratorios atraídos por el crecimiento de Rosario y su región. Sin embargo, también se registran algunas comunidades anteriores a dicho período y asimismo, en las últimas décadas, se conforman nuevos -además del crecimiento poblacional de los ya existentes-. (Figura 2)

Por otro lado, las urbanizaciones cerradas resultan un fenómeno que crece aceleradamente, especialmente desde la década de 1990 hasta la actualidad. Recordemos que, en dicho período, como ocurre en gran parte de Latinoamérica, el Estado nacional argentino atraviesa una gran reforma con cambios estructurales de

13 Este concepto, según definición del INDEC (Instituto Nacional de Estadística y Censos de la República Argentina), permite la delimitación de grupos de pobreza estructural. Por medio del mismo, se registran dimensiones de privación absoluta y se enfoca la pobreza como el resultado de un cúmulo de privaciones materiales esenciales. Ver www.indec.gov.ar. 
orientación neoliberal y privatización, que conduce a una profunda crisis reflejada, por ejemplo, en desempleo, subocupación y precarización laboral. Se registra, entonces, tanto un incremento de pobreza y de asentamientos irregulares, como también se consolidan nuevos emprendimientos inmobiliarios privados como nuevas formas de habitar.

Figura 3. Urbanizaciones cerradas en la localidad de Funes.

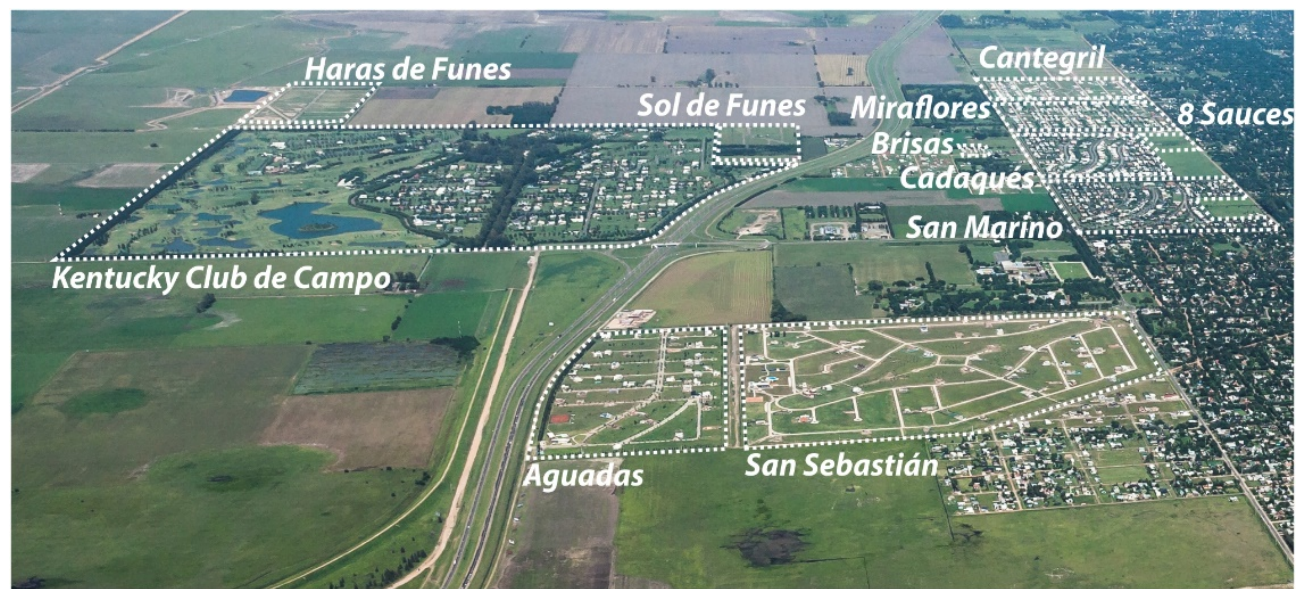

Fuente: Elaboración propia, a partir de archivo fotográfico Metropolitana - Municipalidad de Rosario.

Estas urbanizaciones se postulan como un espacio idílico elegido predominantemente por la clase alta y media-alta, ya sea, por seguir el imaginario asociado a un modo de vida vinculado al campo y al aire libre o debido a no poder acceder al mercado inmobiliario en los centros urbanos, accediendo así, a los nuevos productos ofrecidos por los agentes y promotores -los cuales operan reforzando imaginarios ya instalados o construyendo otros nuevos-. Se persigue entonces, un imaginario vinculado a lo bucólico del campo -cuyo nombre en inglés country hace referencia-, al espacio libre y actividades deportivas dentro de un predio cerrado y controlado por cámaras de seguridad (Galimberti, 2015). Las mismas se desarrollan tanto en la periferia de la jurisdicción de Rosario, como también en los ámbitos territoriales de las distintas localidades que forman parte de su región metropolitana ${ }^{14}$ (Figura 3).

14 Es importante remarcar que ambos casos presentan diferencias en el proceso y las características de la gestión de estos emprendimientos. Rosario -cabecera de la región-, es una ciudad prácticamente urbana que posee más de 950.000 habitantes y tiene una larga tradición de planificación urbano-territorial; mientras que el resto de los poblados pertenecientes a la región son predominantemente rurales y la mayoría presenta menos de 50.000 habitantes. Gran parte de las mismas no tienen Planes Urbanos o Reguladores, denotando una carencia de políticas de planeamiento y control de usos del suelo, existiendo importantes vacíos legales. No obstante, si bien 
Si bien estos contrastes y desigualdades se encuentran en toda la Región Metropolitana de Rosario, a continuación, vamos a focalizarnos en el análisis crítico del corredor sur y del corredor oeste, dado que especialmente en las últimas décadas se incrementan notablemente en sus espacios entre-ciudades nuevas urbanizaciones tanto cerradas y abiertas- que conviven con otros sectores de población localizados en asentamientos irregulares.

\subsection{Corredor sur: Nuevas demandas sobre el paisaje fluvial metropolitano}

Desde la conformación de la región, el río Paraná ha resultado elemento esencial del desarrollo productivo de la misma, mayormente por sus condiciones de puerto natural. No obstante, especialmente en las últimas décadas del siglo XX, existe un cambio de mirada vinculado al ocio y al disfrute recreativo del río y sus islas, que -entre otras acciones- atrae nuevas inversiones para la realización de urbanizaciones privadas frentistas al Paraná. Las localidades metropolitanas que poseen extensiones de suelo rural sobre la ribera son elegidas por parte de promotores inmobiliarios para convertir grandes superficies en nuevas urbanizaciones. Estos emprendimientos tienden a localizarse alejados de los núcleos urbanos, contribuyendo a generar una mayor dispersión territorial, además de mayormente carecer de infraestructuras y servicios urbanos.

Se destaca que existe una tendencia general, especialmente en ciudades de América Latina, a desarrollar nuevas urbanizaciones privadas frente a cursos de agua, que suelen localizarse junto a barrios populares. En Argentina, son de gran relevancia, por ejemplo, los estudios realizados sobre la relación entre estos modos de habitar contrastantes en el municipio de Tigre, como las realizadas sobre el caso de Nordelta y Las Tunas (Michelini y Pintos; 2016); sobre los efectos ambientales que generan estas urbanizaciones cerradas (Ríos y Pírez, 2008); sobre los efectos de dichos enclaves privados en los humedales de la cuenca del río Lujan (Pintos y Narodowski; 2012).

Es así, que estos mega-emprendimientos desarrollados por promotores privados y destinados a grandes barrios cerrados suelen ocupar importantes extensiones de tierras, incrementando en gran medida el territorio urbanizado de la jurisdicción donde se localizan. Por ejemplo, esto se verifica en el poblado de Fighiera, localidad de 5.028 habitantes ${ }^{15}$, cuya planta urbana es de 150 Has aproximadamente. Sin embargo, en su ámbito rural, se desarrolla un barrio cerrado de 80 Has. Es decir, se aumenta en más de un 50\% la superficie urbana de la comuna. (Figura 4)

Esta situación se reitera en diversas localidades ribereñas de la región metropolitana: + En Pueblo Esther, el country náutico privado "La Bahía" de 12 Has; + En General Lagos, se localiza el barrio cerrado "Puerto Paraíso" de 20 Has; y + En

los mecanismos de gestión y planificación son diferentes, en ambos casos el poder del mercado y el capital tiende a prevalecer, contribuyendo a profundizar los contrastes y desigualdades.

15 Según Censo 2010. Es importante destacar que este pueblo tiene una tasa baja de crecimiento poblacional. 
Arroyo Seco, se realiza la urbanización cerrada "Tierra de Sueños Boating" de 100 Has de superficie -en las que se incluyen torres de 25 plantas- (Figura 5). Estos barrios cerrados ribereños poseen amarras, caletas y guarderías de embarcaciones náuticas sobre el frente de agua. Esta situación, además de ocasionar importantes cambios en las dinámicas del ecosistema fluvial -eliminando parte de bajíos y humedales-, también contribuye a aumentar las fragmentaciones socio-espaciales del sector.

Figura 4. Fighiera: Planta urbana y barrio cerrado "Azahares del Paraná".

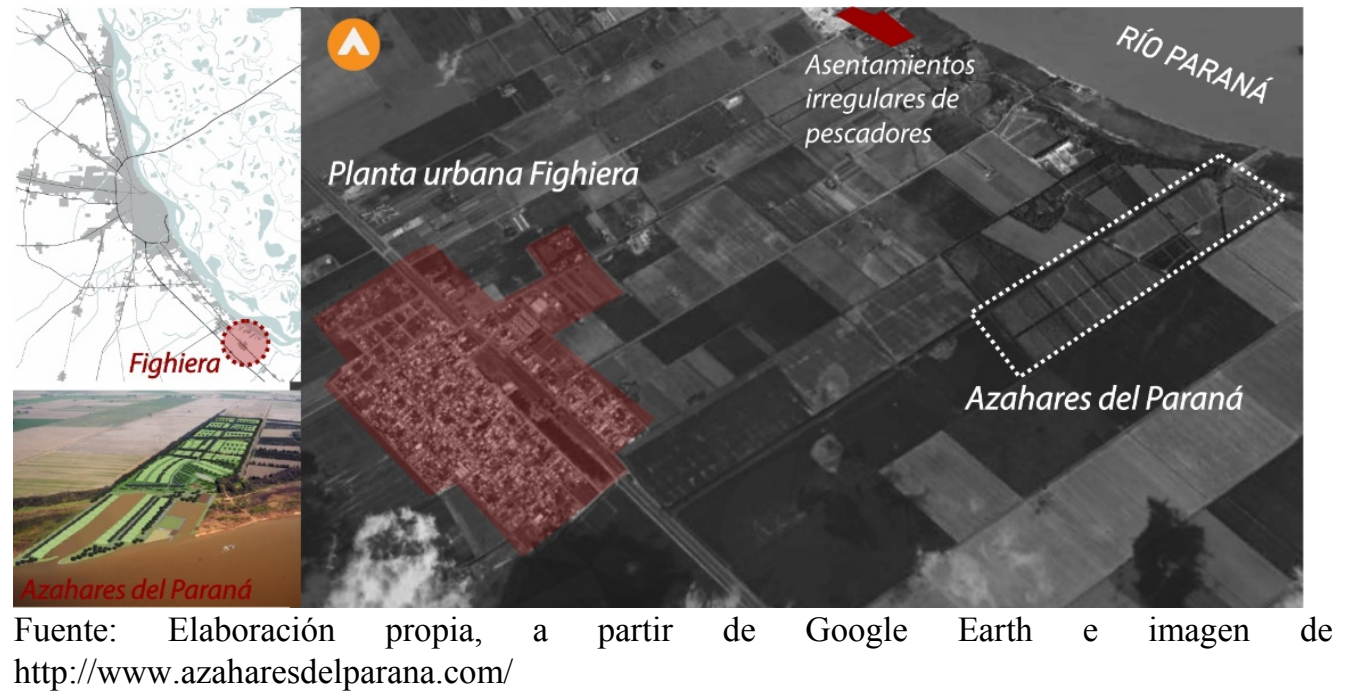

En las barrancas y bajíos de la ribera metropolitana de Rosario se encuentran diversos asentamientos irregulares conformados por familias de pescadores -muchos de estos datan de varias décadas de existencia-. Los mismos se encuentran sometidos a diversas problemáticas y dificultades. Gran parte de estos asentamientos costeros están localizados en áreas de barrancas con problemas de erosión, peligro de derrumbe o de inundación. Otros se localizan en sectores vulnerables, como en márgenes de arroyos altamente contaminados. La mayoría de ellos tienen una importante carencia de servicios e infraestructuras. No obstante, estas comunidades, si bien presentan gran vulnerabilidad socio-ambiental, se niegan a ser relocalizadas, dado que la cercanía al río facilita su trabajo y su medio de subsistencia. (Figura 6)

Esta situación de gran complejidad se agrava al localizarse junto a estos asentamientos grandes urbanizaciones privadas que, además de presentar extensos perímetros cerrados, alteran las dinámicas fluviales con la incorporación de nuevas caletas y amarras sobre la línea de ribera. Retomando los lineamientos planteados por Michelini y Pintos (2016), el mercado y los promotores inmobiliarios tienen un rol central en la apertura de nuevos desarrollos residenciales que atraen grupos de alto poder adquisitivo. De este modo, como se plantea en la literatura especializada 
(Sabatini, 2003; Duhau, 2013), también en los territorios intermedios de la RMR predomina la segregación por las desigualdades de los estratos económicos. El desarrollo de barrios cerrados tiende a profundizar la segregación al generar nuevas barreras -materiales e inmateriales-. Entonces, la ciudad deja de ser un espacio compartido para convertirse en un espacio de alienación, ruptura y negación implícita hacia el otro.

Figura 5. Localidades de General Lagos y Arroyo Seco y su relación con las urbanizaciones cerradas en su jurisdicción.
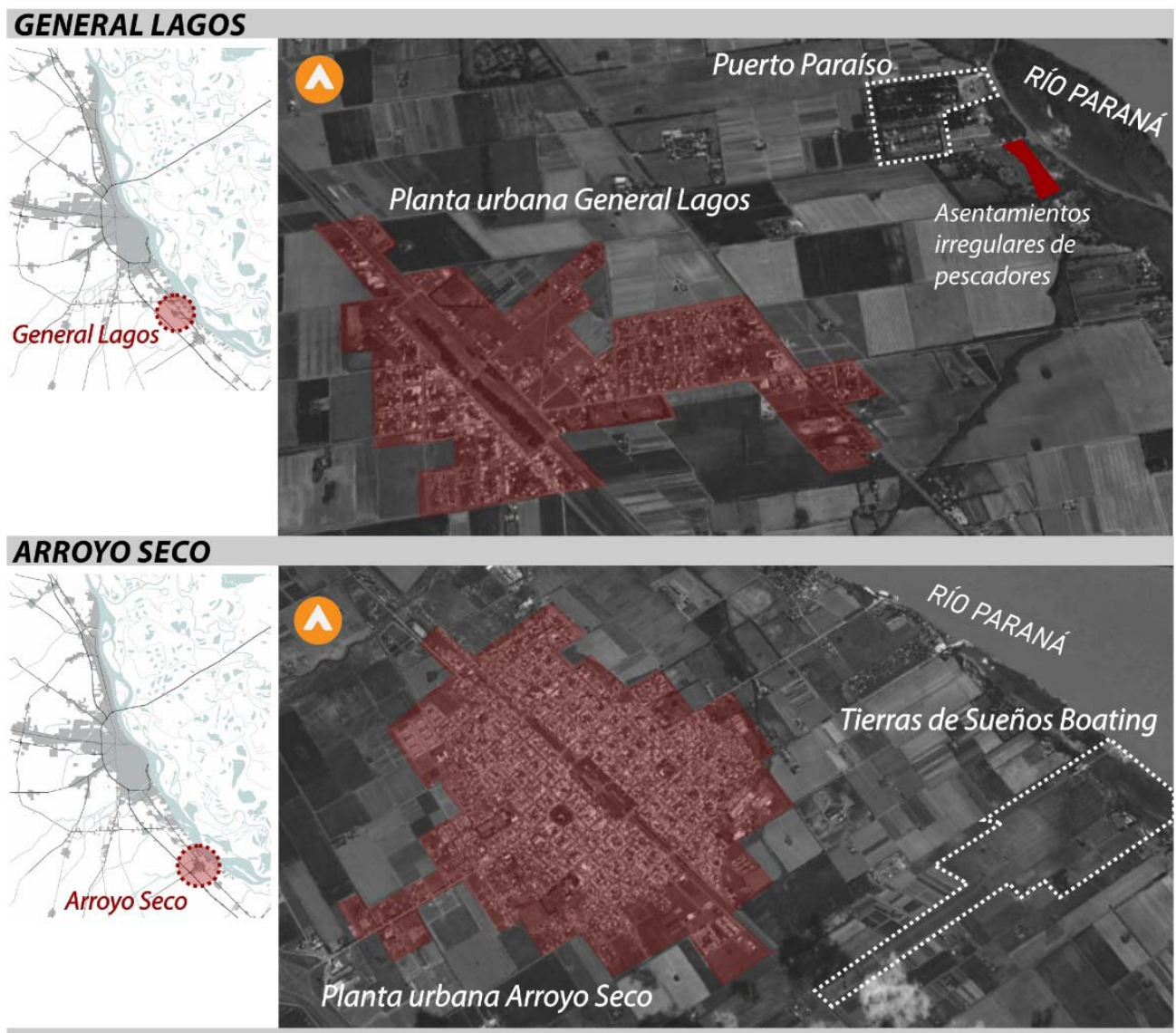

Fuente: Elaboración propia, a partir de Google Earth.

Es importante destacar que las localidades mencionadas, al resultar poblados pequeños, presentan vacíos legales y una débil facultad técnica e institucional para afrontar las fuertes presiones del mercado inmobiliario. Por lo cual, sucumben ante las demandas de promotores que solicitan habilitar grandes superficies de suelo rural para nuevas urbanizaciones -predominantemente privadas y alejadas de la planta 
urbana-. Además, a pesar de las enormes plusvalías que genera este cambio de uso del suelo, los beneficios no se trasladan a la sociedad de la localidad, sino quedan mayormente en manos de los desarrolladores e inversores.

Figura 6. Asentamientos irregulares en la ribera metropolitana de Rosario
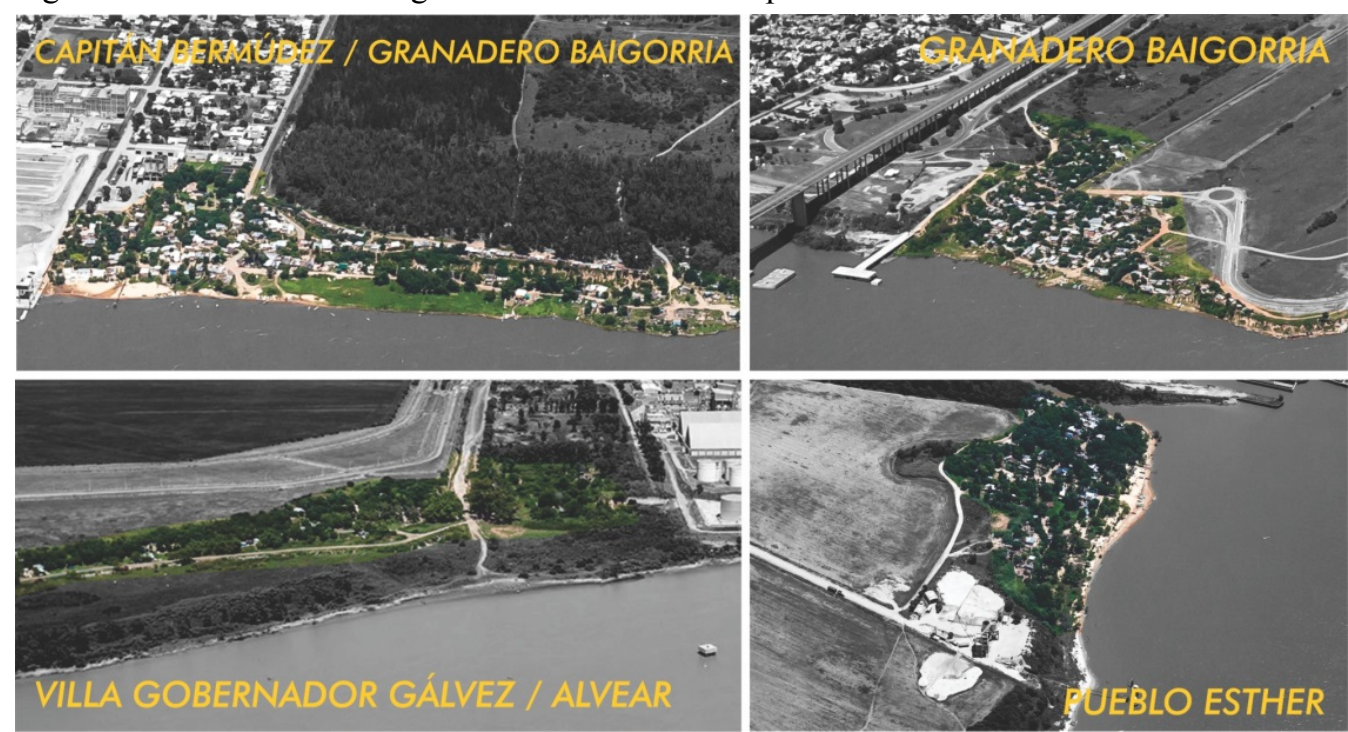

Fuente: Elaboración propia en base a archivo fotográfico Metropolitana - Municipalidad de Rosario.

\subsection{Corredor oeste: El acelerado incremento de nuevas urbanizaciones en el territorio de la RMR}

Se denomina cordón oeste de la RMR a la conurbación que se extiende linealmente sobre la ruta nacional $\mathrm{N}^{\circ} 9$-RN 9-, en dirección oeste de la ciudad central. Las localidades que se encuentran en este corredor se originan a partir de la instalación de estaciones ferroviarias correspondientes al FFCC Central Argentino -ramal con destino a la provincia de Córdoba-. En la década de 1930, se realiza la pavimentación de la RN 9, favoreciendo el incremento urbano de los poblados que atraviesa, principalmente se destaca el crecimiento de las localidades de Funes y de Roldán. (Figura 7)

Entre las décadas 1950-1980, ambas ciudades aumentan notablemente su planta urbana a través de la realización de nuevos loteos, destinados en gran parte a segundas residencias -casas para fines de semanas y vacaciones-. Este corredor metropolitano se posiciona así, desde la segunda mitad del siglo XX, como enclave residencial suburbano que posibilita un mayor contacto con la naturaleza, alejado del caos de la ciudad central, pero rápidamente conectado a la misma a través de la RN 9. 
En las décadas siguientes, esta tendencia se consolida con la construcción de la Autopista Rosario-Córdoba -vía rápida paralela a la RN 9- y especialmente con el boom de los barrios abiertos y cerrados. Por ejemplo, la ciudad de Funes, en menos de veinte años, aumenta su población un 163\%: según censos oficiales, en el año 1991 registra 8.952 habitantes y en el 2010 presenta 23.520 habitantes. En dicho período se realizan más de una veintena de nuevas urbanizaciones -entre cerradas y abiertas-, que transforman más de mil hectáreas de suelo rural a urbano. Es importante destacar que más del $50 \%$ de esa superficie corresponden a más de una docena de barrios privados diseminados en la jurisdicción de Funes, contribuyendo a incrementar la fragmentación socio-espacial (Figura 8).

Figura 7. Corredor oeste de la Región Metropolitana de Rosario

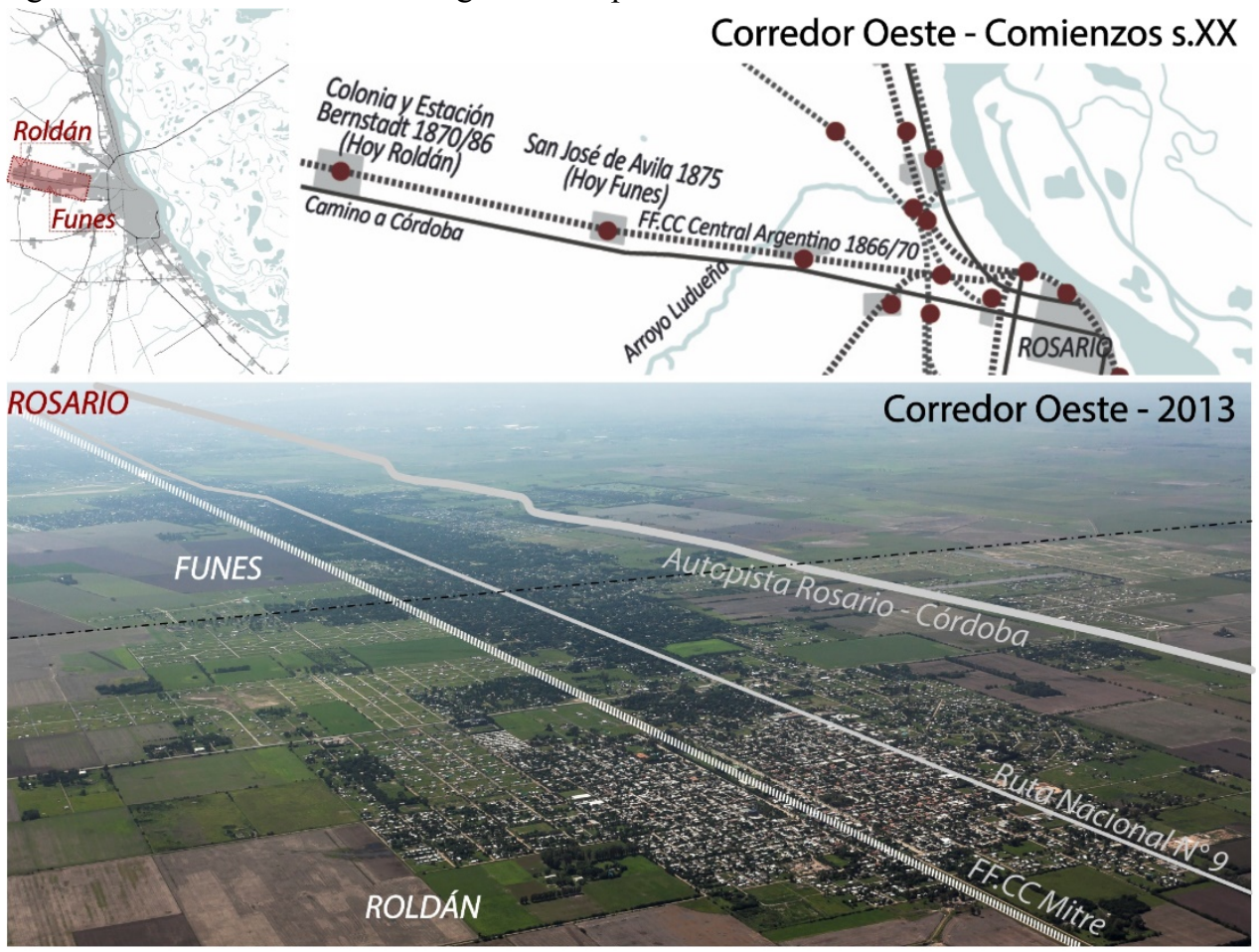

Fuente: Elaboración propia.

Esta situación también se verifica en la localidad de Roldán -lindante a Funes-, en la cual, en las últimas tres décadas, se transformaron más de mil hectáreas de superficie rural a urbana a través de la realización de una veintena de loteos residenciales -entre abiertos y cerrados- (Figura 9). De este modo, la planta urbana de esta ciudad crece vertiginosamente, conformando una conurbación con Funes y el sector oeste de Rosario. Es relevante remarcar que, esta tendencia continúa en curso, a través del proyecto y ejecución de nuevas urbanizaciones. Por ejemplo, en Funes, 
actualmente se encuentra en gestión la realización de un nuevo barrio abierto denominado "La Polola" de 380 Has -previamente de uso agrícola.

Figura 8. Urbanizaciones cerradas y abiertas en Funes (realizadas desde 1990)

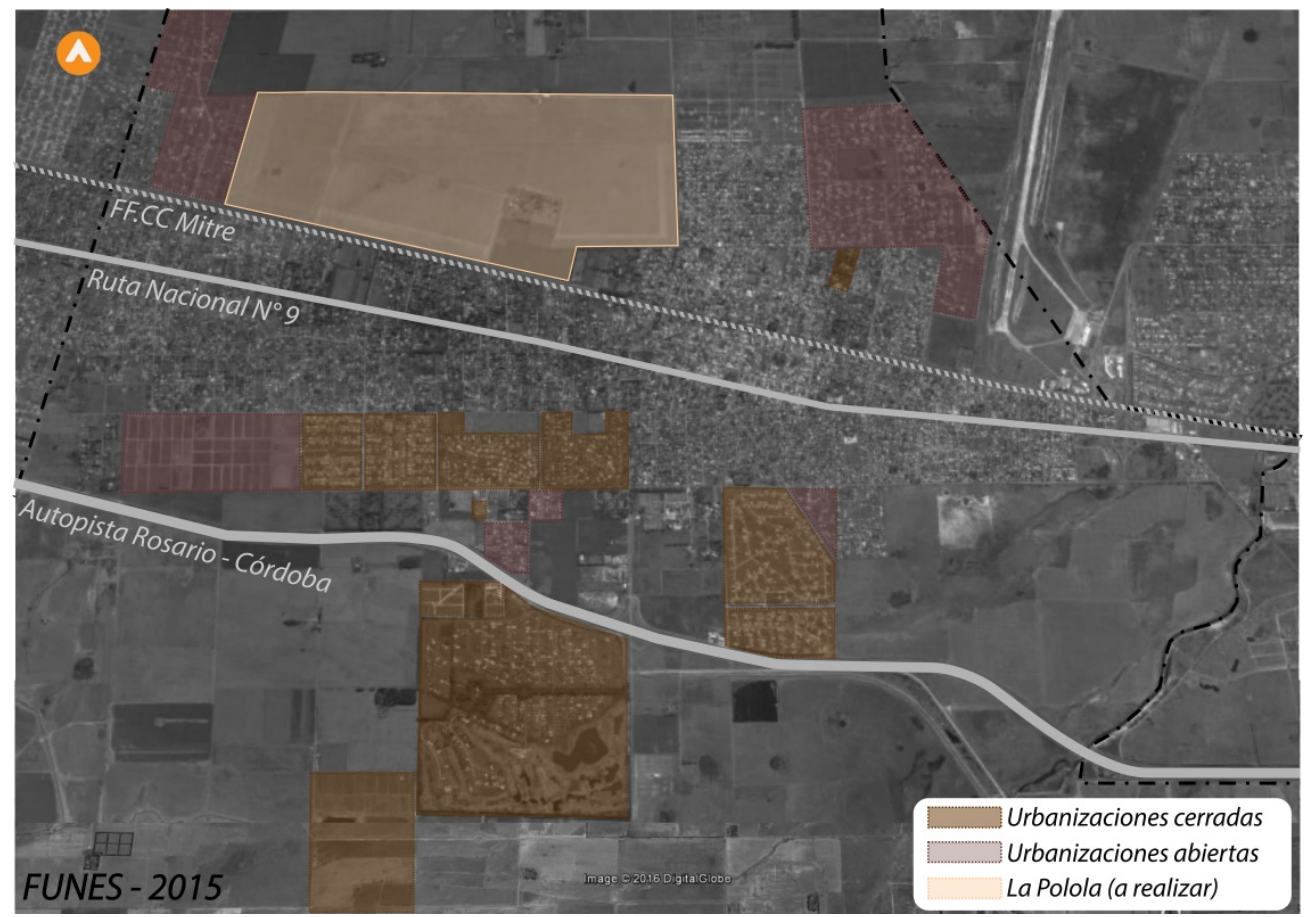

Fuente: Elaboración propia, a partir de Google Earth.

Este proceso acelerado de transformación territorial acarrea diversos impactos tanto sociales como ambientales. Las nuevas urbanizaciones, resultan enclaves que presentan lógicas autónomas que se distancian de las dinámicas de la ciudad tradicional. Por ejemplo, se tiende a eliminar el rol del espacio público como lugar de encuentro, de mixtura social; dado que, en estos desarrollos inmobiliarios el intercambio se realiza entre los propios habitantes del mismo, conduciendo a una mayor segregación. Esto ocurre no sólo con los barrios cerrados, sino también con los loteos abiertos. Los mismos, en su mayoría, suelen tener pocos ingresos al predio general y en su interior se encuentran sectores recreativos que suelen utilizar únicamente sus pobladores. Además, la mayor parte de todos los nuevos residentes no trabajan ni estudian en la localidad en la que se encuentran, sino que se trasladan diariamente a Rosario -gran centro de servicios y actividades-. A su vez, tanto en Funes como en Roldán se registran asentamientos irregulares y habitantes en condición de pobreza, que tienden a quedar cada vez más segregados frente a la construcción de los nuevos muros -aunque a veces verdes- de los enclaves privados. 
Figura 9. Urbanizaciones cerradas y abiertas en Roldán (realizadas desde 1990)

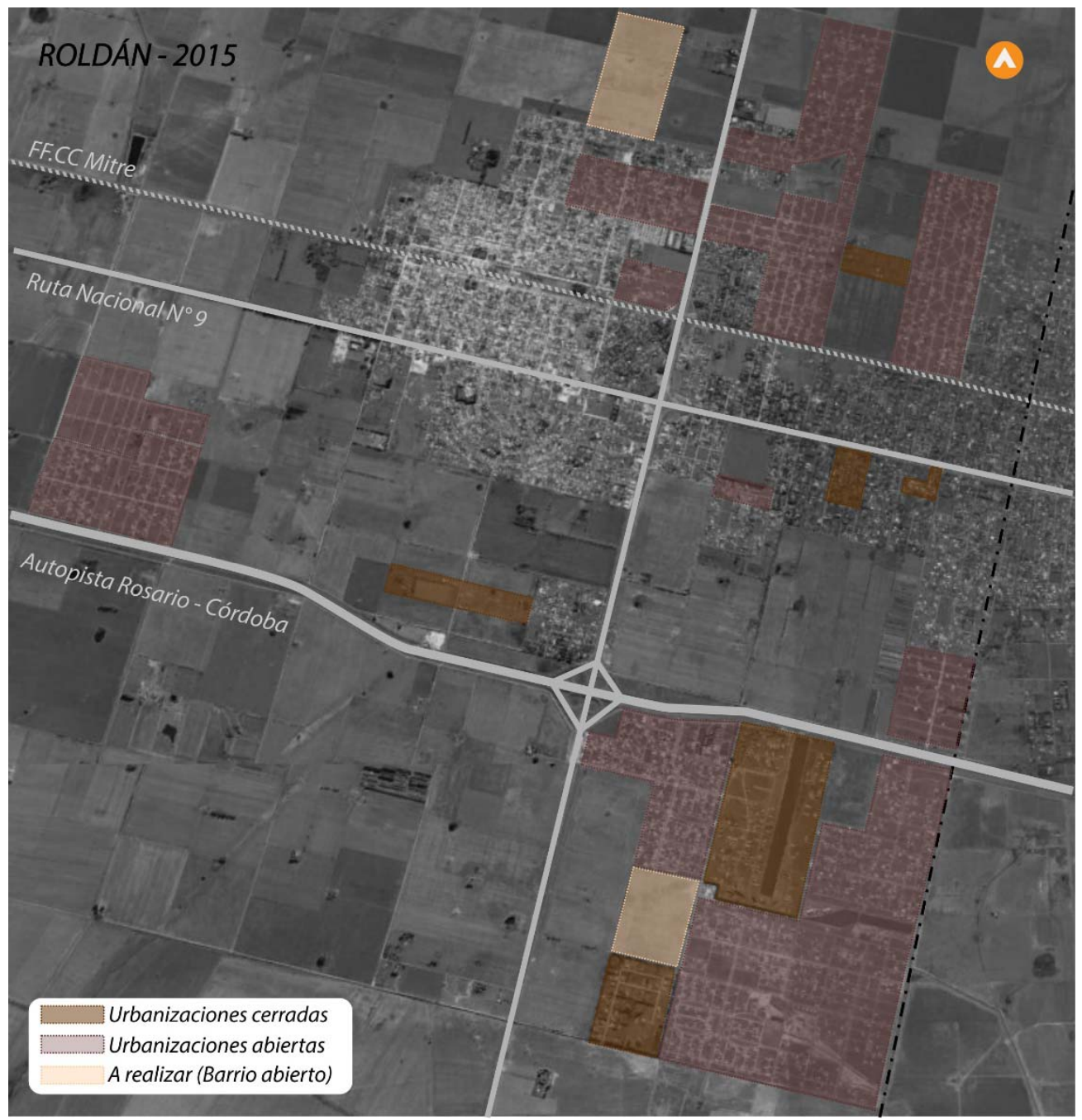

Fuente: Elaboración propia, a partir de Google Earth.

Asimismo, la urbanización de tantas hectáreas de suelo rural contribuye a la impermeabilización del territorio, al aumento del escurrimiento del agua y provoca grandes inundaciones. Gran parte de los terrenos agrícolas que adquieren los promotores inmobiliarios a bajo costo, corresponden a sectores inundables. De manera que, al cambiar las características de los mismos, se generan nuevas inundaciones a los espacios aledaños, perjudicando a gran parte de la población local. Además, esta gran dispersión residencial de baja densidad, causa el aumento del 
automóvil particular y torna más dificultoso el desarrollo de un transporte público eficiente, promoviendo así un modelo de baja sostenibilidad territorial.

Figura 10.

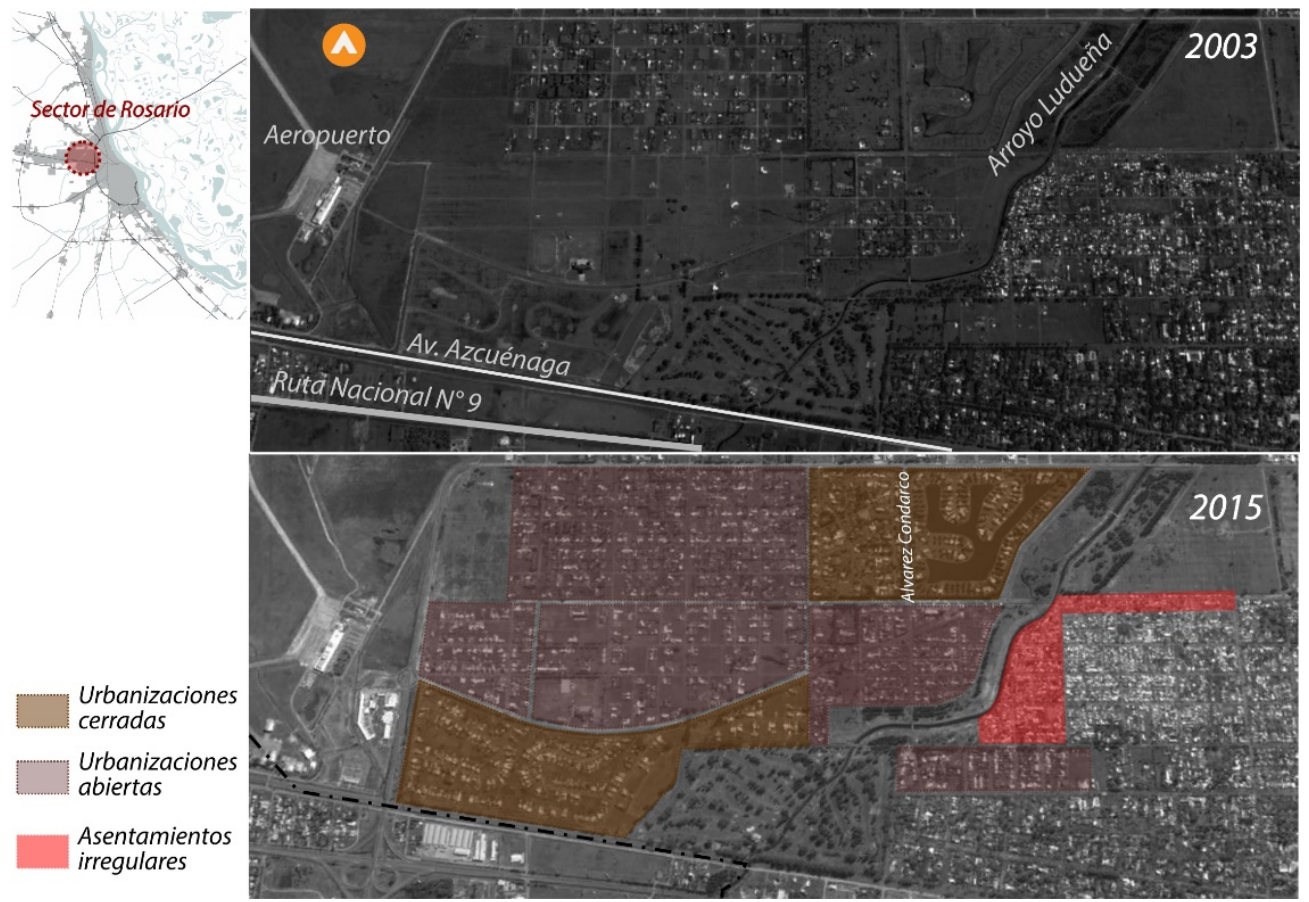

Fuente: Elaboración propia, a partir de Google Earth.

Este gran incremento de nuevas urbanizaciones en el corredor oeste, se verifica no sólo en las jurisdicciones de Roldán y Funes, sino también en su ingreso a Rosario. Vemos en la figura 10, la acelerada transformación que sucede en el noroeste de dicha ciudad, en proximidad al Aeropuerto Internacional -lindante a la ciudad de Funes-, en la última década. La imagen superior corresponde al año 2003 y la inferior del año 2015. En doce años se produce un acelerado proceso de ocupación de tejido residencial, mayoritariamente a través de nuevos barrios abiertos y cerrados. En este sector se encuentran las siguientes urbanizaciones cerradas: + Aldea - Country del Lago -28 Has-; + Aldea Country Tenis -20 Has-; y + Aldea Country Golf -50 Has-. Los barrios abiertos aledaños son: + Barrio San Eduardo -68 Has-; + Aldea -32 Has-; + Portal de Aldea -53 Has-; + Greenes de Fisherton -12 Has-; y + Barrio Residencial Las Torcazas y Hoyo 12 -13 Has-. Además, los mismos se encuentra muy cercanos a otras urbanizaciones privadas como Palos Verdes Country Club -40 Has- y el Country Carlos Pellegrini -20 Has-. 
Sin embargo, este territorio caracterizado por viviendas exentas de gran superficie, con piletas de natación, jardines privados y amenities, como canchas de tenis y golf, lindan con asentamientos irregulares o habitantes que, si bien algunos son dueños de la tierra, presentan numerosas carencias y necesidades. ¿Por qué ocurre esta gran contradicción? Entre los distintos factores, el principal resulta el bajo costo de las tierras de la periferia, en comparación con las localizadas en otros sectores centrales consolidados -con más servicios e infraestructuras-. De manera que, estos espacios resultan de gran atractivo para los promotores inmobiliarios que, movilizados por las lógicas del mercado, realizan desarrollos que les permitan obtener grandes plusvalías. Sin embargo, estos territorios también son elegidos por aquellos que no tienen posibilidad de elegir. Es decir, aquellos habitantes que no pueden acceder a una vivienda propia y se asientan ilegalmente en tierras desocupadas o que adquieren estos lotes por su bajo costo con el fin de ir construyendo gradualmente -y/o precariamente- su propia casa.

En la tabla 1, se detallan las distintas urbanizaciones cerradas analizadas en el presente trabajo. Comprobamos que, en los sectores estudiados, se transforman más de 1.150 hectáreas en grandes componentes privados urbanos. Estas nuevas urbanizaciones, proyectadas por los desarrolladores inmobiliarios, son diseñadas desde sus límites hacia dentro, siendo concebidas como piezas autónomas que van a ser colocadas en un espacio general, sin tener consideración de las relaciones y transformaciones socio-espaciales que generan. Por lo cual, el espacio urbano resulta así cercenado, fragmentado y segregado.

Figura 11. Espacios resultantes entre barrios cerrados. Visuales norte y sur de la calle Álvarez Condarco.
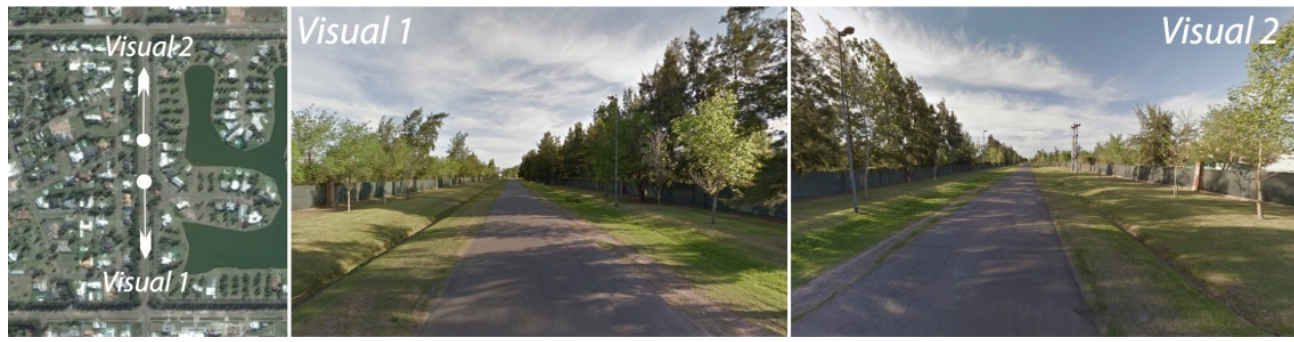

Fuente: Elaboración propia,a partir de Google Street View.

El espacio público resultante se reduce a lo que queda entre los límites de estas urbanizaciones, destinado únicamente a las calzadas de circulación vial. Por ejemplo, la figura 11 muestra la calle Álvarez Condarco entre los barrios cerrados Aldea Tenis y Country del Lago, en Rosario, en la cual, se registra un cerco lineal de 600 metros continuos en ambos frente y se encuentra sólo la vía vehicular -ni siquiera existen veredas-. Estos paisajes se reiteran, con algunas diferencias, en todo el ámbito estudiado. No existe lugar de encuentro con el otro, de intercambio social. Como explica Guy Thuillier, 
Las calles que bordean estas barreras ciegas están condenadas a quedar como vacíos urbanos, como no man's lands. Si hacia el interior producen cohesión, un sentimiento de protección y repliegue, las barreras opacas de los barrios cerrados son hacia el exterior más bien una fuente de anomia y deshacen la ciudad antes que crearla

(Thuillier, 2005:5-20)

Tabla 1. Resumen de barrios cerrados analizados en los corredores sur y oeste de la RMR.

\begin{tabular}{|c|c|c|c|}
\hline \multicolumn{2}{|r|}{ DENOMINACION } & LOCALIDAD & SUPERFICIE \\
\hline \multirow{4}{*}{$\begin{array}{l}5 \\
\text { के } \\
\text { के } \\
8 \\
8 \\
0\end{array}$} & La Bahia & Pueblo Esther & $12 \mathrm{ha}$ \\
\hline & Puerto Paraiso & General Lagos & 20 ha \\
\hline & Azahares del Paraná & Fighiera & 80 ha \\
\hline & Tierra de Sueños Boating & Arroyo Seco & $100 \mathrm{ha}$ \\
\hline \multirow{24}{*}{ 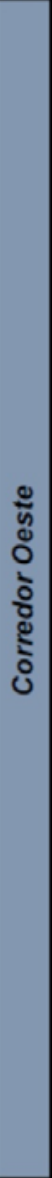 } & Puerto Roldán & Roldán & 90 ha \\
\hline & Los Raigales & Roldán & $40 \mathrm{ha}$ \\
\hline & El Cielo & Roldán & 4,5 ha \\
\hline & Prosperity Lands & Roldán & $10 \mathrm{ha}$ \\
\hline & Punta Chacra & Roldán & $54 \mathrm{ha}$ \\
\hline & Aires de Campo & Roldán & 4 ha \\
\hline & Haras de Funes & Funes & $83 \mathrm{ha}$ \\
\hline & Kentucky Club de Campo & Funes & $242 \mathrm{ha}$ \\
\hline & Cantegril & Funes & 32 ha \\
\hline & Miraflores & Funes & 35 ha \\
\hline & Cadaqués & Funes & $35 \mathrm{ha}$ \\
\hline & San Marino & Funes & 34 ha \\
\hline & San Sebastián & Funes & 74 ha \\
\hline & Aguadas & Funes & $30 \mathrm{ha}$ \\
\hline & Sol de Funes & Funes & $4,3 \mathrm{ha}$ \\
\hline & Río de los Pájaros & Funes & $3 \mathrm{ha}$ \\
\hline & Brisas de Funes I y II & Funes & $1 \mathrm{ha}$ \\
\hline & Brisas de Funes III y IV & Funes & $1 \mathrm{ha}$ \\
\hline & Ocho Sauces Condominio & Funes & 3,5 ha \\
\hline & Aldea - Country del Lago & Rosario & $28 \mathrm{ha}$ \\
\hline & Aldea - Country Tenis & Rosario & 20 ha \\
\hline & Aldea - Country Golf & Rosario & 50 ha \\
\hline & Palos Verdes Country Club & Rosario & 40 ha \\
\hline & Country Carlos Pellegrini & Rosario & 20 ha \\
\hline
\end{tabular}

Fuente: Elaboración propia 
Los espacios urbanos públicos se reducen así a vías de transporte automotor, meros conectores entre los distintos desarrollos inmobiliarios. Al recorrer las calles entre los mencionados barrios cerrados y abiertos no se suelen encontrar peatones tampoco hay infraestructura adecuada para los mismos-, la movilidad tiende a realizarse en autos privados y las actividades recreativas y sociales sólo se realizan en el ámbito privado. Esta situación cambia en los asentamientos aledaños de bajos recursos, ya que los pasajes y calles entre viviendas resultan los espacios de encuentro entre los habitantes del barrio -porque tampoco tienen otros espacios a los que puedan acceder- (Figura 12). Paisajes opuestos, espacialmente lindantes pero muy distantes socialmente, se multiplican en la periferia rosarina en los últimos años.

Figura 12. Asentamientos irregulares en el sector de estudio.

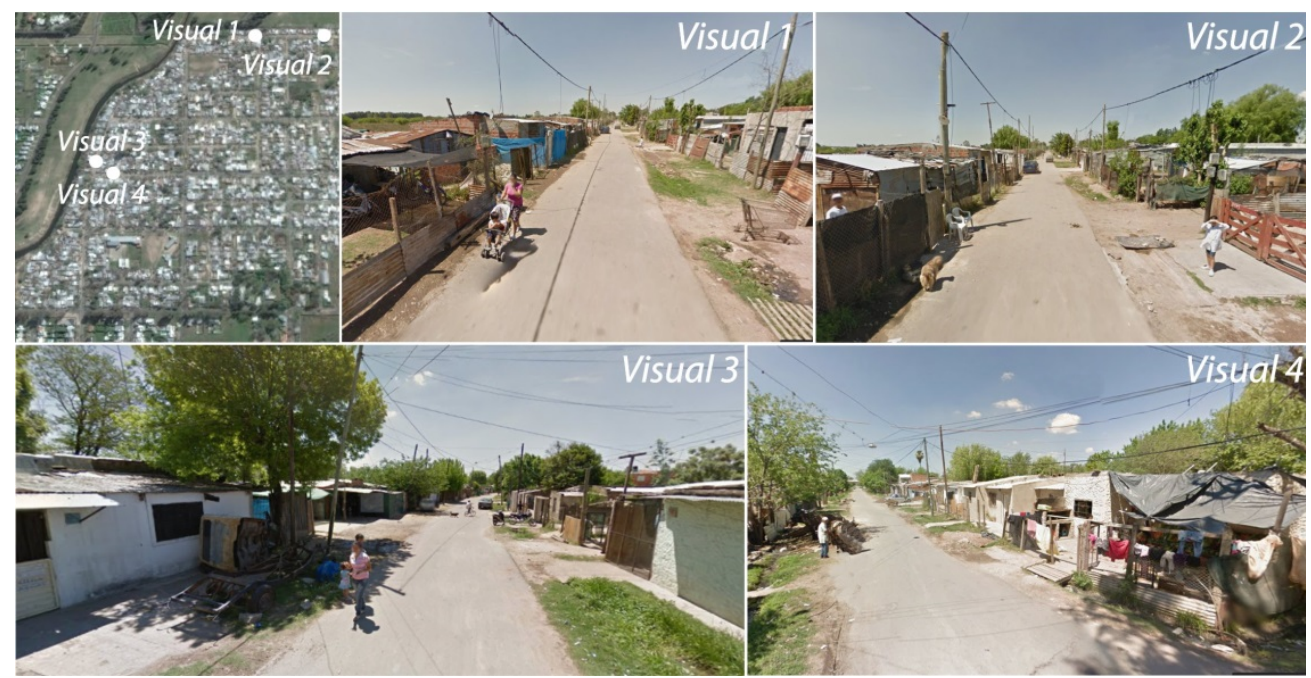

Fuente: Elaboración propia, a partir de Google Street View.

\section{Conclusiones}

Las transformaciones que suceden en las últimas décadas en los territorios intermedios metropolitanos producen diversos impactos socio-ambientales que contribuyen a profundizar las desigualdades e inequidades. En la Región Metropolitana de Rosario, vemos que la presión del mercado y el capital conducen a consumir las reservas de suelo existentes, cambiando de uso rural a urbano grandes superficies de tierras. Esto nos lleva a reflexionar sobre el rol de los diversos actores intervinientes, los efectos resultantes y las directrices de acción necesarias para revertir los mismos.

Por un lado, registramos la carencia de un marco legal claro e integrado entre los distintos niveles estatales. Existen algunos vacíos normativos, que son aprovechados por los promotores inmobiliarios para generar grandes plusvalías. Sin embargo, las 
mismas quedan mayormente en manos de los promotores, dado que también faltan instrumentos de captación de las mismas para el beneficio de la localidad y sus habitantes.

Por otro lado, estas transformaciones contribuyen a aumentar las vulnerabilidades ambientales y sociales. El incremento del consumo del territorio intermedio para usos urbanos genera diversas problemáticas como: el aumento de la impermeabilización del suelo -agravando las inundaciones-; la dispersión territorial, que ocasiona la demanda de nuevas infraestructuras y servicios, dificulta la movilidad -conduciendo a un mayor uso del automóvil particular- y reduce la sostenibilidad territorial.

A su vez, estas nuevas urbanizaciones -en primer lugar las cerradas, pero también ocurre con las abiertas-, resultan enclaves inconexos desvinculados con el resto del territorio. En los casos estudiados de la región, vemos que no presentan relaciones con el entorno próximo, ni con los vecinos pre-existentes. Se denota así un gran aumento de la fragmentación socio-territorial, profundizando las problemáticas sociales cuando se encuentran próximas a comunidades vulnerables. A través de estos nuevos modos de habitar se tiende a destruir la esfera del intercambio de sociabilidad urbana.

Sin embargo, estas tendencias de transformación se encuentran instaladas en nuestras regiones metropolitanas a nivel global, por lo cual, plantear su prohibición o su negación no resulta una respuesta posible. Es necesario, en cambio, adentrarse en estos procesos y profundizar su conocimiento, a fin de desarrollar nuevos instrumentos y estrategias de planificación que den lugar a las demandas existentes pero a través de un fuerte acompañamiento estatal; a fin de evitar nuevos perjuicios y problemas y lograr, en cambio, una integración armónica de la sociedad y su territorio.

Para revertir la fragmentación y reducir los contrastes y desigualdades se requiere un mayor compromiso de toda la población, gestionar ámbitos de debate de amplia participación y mejorar las articulaciones políticas en todos los niveles estatales. Hay que abogar por un desarrollo integrado de lineamientos políticos, económicos y sociales que apunten al aumento de las capacidades individuales y colectivas, a fin de alcanzar una mayor inclusión y equidad.

\section{Bibliografía}

Blanco, J.; San cristóbal, D. (2012): Reestructuración de la red de autopistas y metropolización en Buenos Aires. Riurb, 8, 73-88. Disponible en: http://www.riurb.com/n8/08_riurb.pdf

Cuenya, B. (2000): Globalización y políticas urbanas. Transformaciones de las políticas urbanas en la ciudad de Buenos Aires. Sociológica, 15(42), 37-57. Disponible en: $\mathrm{http}: / /$ www.revistasociologica.com.mx/pdf/4203.pdf

Clichevsky, N. (2000): Informalidad y segregación urbana en América Latina. Una aproximación.

De Castro, R.; Franchelli, E.; Piccolo; E. (1996): Asentamientos Irregulares de Rosario. Actualización 96. Rosario, Fundación Banco Municipal de Rosario. 
Douglas Young, P.; Wood, B.; y Keil, R. (2011): In-between infrastructure: Urban Connectivity in an Age of Vulnerability. Praxis (e) Press. Critical Topographies Series.

Duhau, E. (2013): La división social del espacio metropolitano. Una propuesta de análisis. Nueva Sociedad, 243, 79-91. Disponible en:

http://www.comisionporlamemoria.org/investigacionyensenanza/materiales/volumen13/doc s/3.Identidad-del-barrio/Texto\%207.pdf

Font, A. (2007): La explosión de la ciudad. Transformaciones territoriales en las regiones urbanas de la Europa Meridional. España, Ministerio de Vivienda.

Galimberti, C. (2015): La reinvención del río. Procesos de transformación en la ribera de la Región Metropolitana de Rosario. Rosario, UNR Editora.

Hidalgo, R. (2004): De los pequeños condominios a la ciudad vallada: las urbanizaciones cerredas y la nueva geografía social en Santiago de Chile (1990-2000). EURE (Santiago), 30 (91), 29-52. http://dx.doi.org/10.4067/S0250-71612004009100003

Janoschka, M. (2002): El nuevo modelo de la ciudad latinoamericana: fragmentación y privatización. EURE (Santiago), 28 (85), 11-20. http://dx.doi.org/10.4067/S025071612002008500002.

Kaztman, R. (2008): Seducidos y abandonados: pobres urbanos, aislamiento social y políticas públicas. Disponible en:

https://utexas-ir.tdl.org/bitstream/handle/2152/4092/kaztman.pdf?sequence=2\&isAllowed=y

Michelini, J.J.; Pintos, P. (2016): Metropolitan expansión and new socio-spatial segregation scenarios in contemporary Argentina. The case of Nordelta-Las Tunas (Buenos Aires). Habitat International, 54, 40-49.

Mongin, O. (2006): La condición urbana: la ciudad a la hora de la mundialización. Buenos Aires, Editorial Paidós.

Piccolo, E.; Franchelli, E.; de Castro, R. (1992): Grupo de estudio: Asentamientos Irregulares de Rosario. Rosario, Fundación Banco Municipal de Rosario.

Pintos, P.; Narodowski, P. (2012): La privatopía sacrílega. Efectos del urbanismo privado en humedales de la cuenca baja del río Luján". Buenos Aires, Imago Mundi.

Prévôt-Schapira, M. F. (2001): Fragmentación espacial y social: conceptos y realidades. Perfiles latinoamericanos: revista de la Facultad Latinoamericana de Ciencias Sociales, Sede México, (19), 33-56. Disponible en:

http://dialnet.unirioja.es/servlet/articulo?codigo $=2212216$

Ríos, D.; Pírez, P. (2008): Urbanizaciones cerradas en áreas inundables del municipio de Tigre: ¿producción de espacio urbano de alta calidad ambiental?. EURE (Santiago), 34 (101), 99119. http://dx.doi.org/10.4067/S0250-71612008000100005.

Sabatini, F. (2003): La segregación social del espacio en las ciudades de América Latina. Washinton D.C, Banco Interamericano de Desarrollo., Departamento de Desarrollo Sostenible.

Sabatini, F.; Brain, I. (2008): La segregación, los guetos y la integración social urbana: mitos y claves. EURE (Santiago), 34 (103), 5-26. http://dx.doi.org/10.4067/S025071612008000300001 .

Sieverts, T. (2004): Cities without cities. An interpretation of the Zwischenstadt. Taylor \& Francis e-Library. 
Svampa, M. (2001): Los que ganaron: la vida en los countries y barrios privados. Buenos Aires, Biblos.

Tardín Coelho, R. (2007): Los paisajes de la ciudad oculta. En Nogué, J. (Ed.): La construcción social del paisaje. Madrid, Biblioteca Nueva, 199-218.

Torres, H. (2001): Cambios socioterritoriales en Buenos Aires durante la década de 1990. EURE (Santiago), 27 (80), 33-56. http://dx.doi.org/10.4067/S0250-71612001008000003

Thuillier, G. (2005): El impacto socio-espacial de las urbanizaciones cerradas: el caso de la Región Metropolitana de Buenos Aires. EURE (Santiago), 31(93), 5-20. http://dx.doi.org/10.4067/S0250-71612005009300001

Valenzuela Rubio, M. (1985) Los espacios periurbanos. Acta, Discursos, Ponencias y Mesas Redondas del IX Coloquio de Geografos Españoles, Mucia, Universidad de Murcia. Disponible en: http://www.uam.es/gruposinv/urbytur/documentos/Valenzuela/IXColoquio1986.pdf

Vidal-Koppmann, S. (2007): La expansión de la periferia metropolitana de Buenos Aires. "Villas miseria" y "Countries": De la ghettización a la integración de actores en el desarrollo local urbano. Scripta Nova, Revista Electrónica de Geografía y Ciencias Sociales, XI, 245 (42), Barcelona, Universidad de Barcelona. Disponible en: http://www.ub.es/geocrit/sn/sn-24542.htm 